\title{
12. GEOCHEMICAL STUDIES OF THE CRETACEOUS-TERTIARY BOUNDARY IN ODP HOLES 689B AND 690C 1
}

\author{
Helen V. Michel, ${ }^{2}$ Frank Asaro, ${ }^{2}$ Walter Alvarez, ${ }^{3}$ and Luis W. Alvarez ${ }^{4}$
}

\begin{abstract}
In a study of ODP Hole 689B no iridium (Ir) anomaly was found in Sections 1 through 6 of Core $25 \mathrm{X}$ or in Core $26 \mathrm{X}$ from the top down to section 2, 3-12 cm. The background $\mathrm{Ir}$ abundance averaged 11 parts per trillion (ppt) and a clay-enriched region had nearly the same average, $26 \pm 12 \mathrm{ppt}$. If the Cretaceous-Tertiary (K-T) contact is in the region studied, then sedimentation was not continuous, and the K-T boundary was probably either not deposited or it was eroded away.

In a study of Cores $15 \mathrm{X}$ and $16 \mathrm{X}$ of ODP Hole $690 \mathrm{C}$, an iridium peak with a maximum abundance of $1566 \pm 222$ ppt was found in Section 4 of Core $15 \mathrm{X}$ at $39-40 \mathrm{~cm}$ with a half-width of $6.6 \mathrm{~cm}$. Background abundances were $\sim 15$ ppt and distinctly higher Ir abundances were observed from $119 \mathrm{~cm}$ below to $72 \mathrm{~cm}$ above the main peak. The Ir distribution below the main peak is attributed to bioturbation by organisms with burrows extending at least $0.4 \mathrm{~m}$. The $\mathrm{Ir}$ distribution above the main peak may be due to the same cause but other explanations may be significant.

There are variable enrichments of clay in the mainly $\mathrm{CaCO}_{3}$ sediment of Core $15 \mathrm{X}$, and the stratigraphically lowest part of the most abundant clay deposits is found (within $2 \mathrm{~cm}$ ) in the same position as the main Ir peak. The clay deposit, which is estimated to be about $50 \%$ of the sediment, extends upward $\sim 19 \mathrm{~cm}$ and then slowly decreases to a background level of $10 \%$ over $1 \mathrm{~m}$. The degree of homogeneity of the clay-rich interval suggests it was not due to episodic volcanism but may have been due to a decrease of the $\mathrm{CaCO}_{3}$ deposition rate which was possibly triggered by the impact of a large asteroid or comet on the Earth.
\end{abstract}

\section{INTRODUCTION}

The shipboard scientific party from Leg 113 observed a clayrich interval whose stratigraphically lowest part occurred at the same level as the change in biota from Cretaceous to Tertiary forms (Barker, Kennett, et al., 1988) in ODP Holes 689B and $690 \mathrm{C}$. They were interested in comparing their data with the stratigraphic position of the Cretaceous-Tertiary (K-T) iridium anomaly, if it could be detected, and requested our group at the Lawrence Berkeley Laboratory (LBL) to make the iridium measurements. We were interested in determining whether volcanism was associated with the impact of an asteroid or comet (which we believe was responsible for the K-T iridium anomaly), and the shipboard samples were very propitious for our purpose.

\section{LITHOLOGY}

The Hole 689B K-T region is described as semilithified foraminifer-bearing nannofossil ooze/chalk in the shipboard report. A clay-rich layer was detected in Core $25 \mathrm{X}$, Section 5, 50-85 $\mathrm{cm}$, as a minor lithology. There was a sudden extinction of almost all species of planktonic foraminifers and calcareous nannofossils which coincided with the beginning of the clay-bearing layer (Barker, Kennett, et al., 1988).

The Hole $690 \mathrm{C} \mathrm{K}-\mathrm{T}$ region is described as a foraminifer and mud-bearing nannofossil chalk. There is a strongly bioturbated, zeolite-rich, pale brown layer attributed to the K-T boundary in Core $15 \mathrm{X}$, Section $3,115 \mathrm{~cm}$, to Section 4, $50 \mathrm{~cm}$ (Barker, Kennett, et al., 1988).

\footnotetext{
${ }^{1}$ Barker, P. F., Kennett, J. P., et al., 1990. Proc. ODP, Sci. Results, 113: College Station, TX (Ocean Drilling Program).

2 Lawrence Berkeley Laboratory, Building 70, MS 110A, Cyclotron Road, Berkeley, CA 94720.

3 Department of Geology, University of California, Berkeley, CA 94720.

4 Professor Alvarez died 1 September 1988.
}

\section{EXPERIMENTAL PROCEDURES}

\section{Sample Preparation}

Samples were dried at $110^{\circ} \mathrm{C}$ and then ground with an agate mortar and pestle. From each ground sample $100 \mathrm{mg}$ of powder was weighed and encapsulated in 0.020-cm-thick $99.9995 \%$ pure $\mathrm{Al}$ foil prior to neutron irradiation. The encapsulated samples were irradiated in the University of Missouri reactor for $144 \mathrm{hr}$ at a flux of $2.3 \times 10^{13}$ neutrons $/ \mathrm{s}-\mathrm{cm}^{2}$.

\section{Measurement Procedures for Iridium}

All irradiated samples were measured with the Iridium Coincidence Spectrometer (ICS) (Asaro et al., 1988; Asaro et al., 1987) at times ranging from 3 to 8 months after the irradiation. The ICS has twin crystals of intrinsic Ge, $5 \mathrm{~cm}$ diameter by $5 \mathrm{~cm}$ long with faces $20 \mathrm{~mm}$ apart. The activated encapsulated sample rests between the two crystals each of which can function with up to 100,000 gamma rays per second (CPS). For maximum efficiency the irradiation dosage and the length of time between the irradiation and measurement are chosen to give an estimated 40,000 CPS. The Ge crystals each detect Ir gamma rays of 316.5 and $468.1 \mathrm{keV}$ energy, and so two sets of coincidences between the two energies can be determined. There is a background in the two crystal detectors of $\sim 70$ counts per hour due to Compton scattering of coincident pairs of gamma rays from ${ }^{46} \mathrm{Sc}$ and ${ }^{60} \mathrm{Co}$ which are prominent radiations (particularly ${ }^{46} \mathrm{Sc}$ ) in irradiated geochemical samples. To reduce the Compton background, the Ge crystals are surrounded by twin tanks of mineral oil, doped with a scintillator and a wave shifter, which act as Compton-gamma-ray detectors. Whenever a gamma ray triggers the mineral oil detectors, the resulting light is detected with photomultiplier tubes which then veto any coincidence detected by the Ge crystals. There is still a residual Compton-scattered background of 2-6 coincidences/hr. The background is estimated from coincidences between $316.5 \mathrm{keV}$ radiation in one detector and $\sim 500 \mathrm{keV}$ radiation in the other and then subtracted from the observed counts. 
The radioactivity in irradiated calcareous samples is roughly proportional to their clay content. When very calcareous samples were measured about 1 month after irradiation, a sensitivity of $50 \mathrm{ppt}(95 \%$ confidence level) was obtained in 7-min counts. (Three counts in $7 \mathrm{~min}$ corresponded to $50 \mathrm{ppt} \mathrm{Ir}$, and 0 counts were obtained.) Samples with clay contents above $15 \%$ had progressively poorer sensitivity. In the present work, counting times varied from $7 \mathrm{~min}$ to $14 \mathrm{hr}$ depending on the sensitivity or precision desired.

\section{Measurement Procedures for Other Elements}

After measurement of iridium, the samples considered to be the most interesting were counted again with conventional gamma ray analyzers to measure long-lived radionuclides. These neutron activation measurements may have uncertainties of $\sim 5 \%$ in accuracy due to systematic uncertainties. Because the relative elemental abundances in the samples can be important, we have included the precision of measurement also.

$\mathrm{X}$-ray fluorescence measurements for $\mathrm{Fe}$ and $\mathrm{Mn}$ in a few samples were made by Harry R. Bowman of LBL with newly developed equipment similar to a prototype model previously reported (Hebert and Street, 1974). Comparison of Fe measurements by X-ray fluorescence and neutron activation analysis on the same samples showed average deviations of $\sim 4 \%$. Robert Giauque of LBL also made some measurements for Mn with another X-ray fluorescence system (Giauque et al., 1973).

\section{Contamination}

Gold and iridium contamination arising from gold and platinum jewelry has previously been reported (Alvarez et al., 1982). Commercially pure $\mathrm{Al}(99.5 \%)$ that we measured contained 16 ppt Ir. Six 9's (99.9995\% pure) Al did not contain any detectable Ir at the ppt level. Copper metal contained levels of about $1000 \mathrm{ppt}$ Ir and stainless steel had $100,000 \mathrm{ppt}$ Ir, possibly due to the $\mathrm{Cr}$ in the alloy. Contaminations of $1-50 \times 10^{-12} \mathrm{gm}$ of $\mathrm{Ir}$ have been observed in about $1 \%$ of our samples either with the powder or on the Al capsule. In at least some instances, this contamination is a single minute particle, which is insoluble in aqua regia. When individual samples are found to have an anomalously high $\mathrm{Ir}$ abundance, the samples are split into two parts and one or both splits are remeasured. If one of the splits is definitely lower in Ir than the whole sample, the lower value is selected. Occasionally, splitting is continued to insure that the contamination is in one particle. Enrichment of the contaminated fraction in a previous experiment by a factor of $1,000,000$ was made without detectable loss of the Ir contaminant. Air samples in our laboratory over a 1-yr period showed iridium contents which varied roughly with the contamination levels in our samples. At one time metallic iridium powder was used in our building, and the observed airborne and sample contaminations may be due to iridium in the air conditioning ducts.

When hundreds of samples have been measured, abrasion of the irradiated $\mathrm{Al}$ capsules in the ICS does produce a background of ${ }^{46} \mathrm{Sc}$ radiations in the ICS, as Sc at the $0.1 \mathrm{ppm}$ level is a common contaminant of $\mathrm{Al}$. Also, residual rock dust on the outer surfaces of the capsules abrades in the ICS and produces a cumulative background of long-level radioactivities, e.g., ${ }^{46} \mathrm{Sc},{ }^{152} \mathrm{Eu}$, and ${ }^{60} \mathrm{Co}$. The ICS is decontaminated every few months, and samples expected to have high $\mathrm{Ir}$ contents are prepared in a different area than other samples.

Silver and zinc contaminants have also been observed in the ICS and on sample surfaces. The former probably arose from silver jewelry and the latter as a corrosion product of unpainted galvanized iron in our sample preparation room. The jewelry is now removed during sample preparation and the galvanized iron has been painted.
By using high purity $\mathrm{Al}$ capsules and special care in sample preparation, we have eliminated the most likely sources of $\mathrm{Ir}$ contamination. The remaining source of contamination (that we know about) in the air ducts can be identified and removed by measurement of splits of the irradiated samples.

The method of removing minute airborne $\mathrm{Ir}$ contamination from our samples would also remove single cosmic spherules. The increased confidence in the validity of our data that we obtain by using the splitting technique more than compensates for the possible loss of data on cosmic Ir-bearing nuggets. In the present study, only one sample, $690 \mathrm{C}-15 \mathrm{X}-4,52-53 \mathrm{~cm}$, was split and recounted for Ir, and that sample was found to be uncontaminated by airborne Ir.

\section{RESULTS}

The iridium abundance data for Hole 689B are shown in Figure 1. Selected groupings of the data are shown in Table 1. The best values of the average iridium abundances above, below, and in the clay-enriched layer are shown in Table 2. The abundances of iron and several other elements ( $\mathrm{Co}, \mathrm{Cs}, \mathrm{Eu}$, and $\mathrm{Sc})$ in selected parts of the K-T region are shown in Table 3 .

The iridium data for Hole $690 \mathrm{C}$ are shown in Figure 2. Iron abundances and the ratios of the abundances of $\mathrm{Ir}, \mathrm{Co}, \mathrm{Cs}$, and $\mathrm{Sc}$ to $\mathrm{Fe}$ are shown in Figure 3. The background iridium abundances are shown in Table 4 along with several higher precision measurements which shows how the iridium increases downsection from the background region. The best values of the average iridium abundances in the background regions are shown in Table 5 . The abundance data for Ir and 12 other elements is shown in Table 6.

Measurements by X-ray fluorescence of six samples from Hole 690C (Core 15X, Section 4, 42-48 cm) showed Ca elemental abundances equal to $58 \%-71 \% \mathrm{CaCO}_{3}$; abundances and ratios of $\mathrm{Fe}$ to the noncalcareous mass of 0.046 with a RMSD (defined in Table 1) of 0.003 . The average ratio of $\mathrm{SiO}_{2}$ (measured as $\mathrm{Si}$ ) to the noncalcareous mass was 0.569 with a RMSD of 0.034 and the same ratio for $\mathrm{Al}_{2} \mathrm{O}_{3}$ (measured as $\mathrm{Al}$ ) was 0.123 \pm 0.011 . The total measured mass of oxides (with $\mathrm{Ca}$ expressed as carbonate) varied from $90 \%$ to $96 \%$ but $\mathrm{Na}, \mathrm{K}, \mathrm{Cl}$, Ti, water, organic materials, and minor elements were not measured.

\section{DISCUSSION}

\section{Hole 689B}

There is no indication of the K-T iridium anomaly in Hole $689 \mathrm{~B}$ as seen in Figure 1. This Ir anomaly has been detected at or very near the K-T boundary defined by lithological or paleontological changes in many sections world-wide (Alvarez, $1987 \mathrm{a}, \mathrm{b})$. From paleontological measurements by the shipboard party, the K-T boundary would be expected in the region studied here. It seems likely then that the sedimentation was not continuous and the K-T boundary sediments were not deposited or were eroded away. Measurements of iron (a component of clay) suggest an enhancement of clay in Section 5. If we assume the same ratio of iron to noncalcareous fraction $(4.8 \%)$ that we determined in Hole $690 \mathrm{C}$, the maximum clay content is $\sim 16 \%$ and background is $\sim 5 \%$. The average $\mathrm{Ir}$ in the region above and below the clay-enrichment is about the same, $11.5 \mathrm{ppt}$. When the measurement errors are considered, these data suggest the sediment accumulation rate before and after the clay deposition was the same within a factor of two.

\section{Hole 690C}

A well-defined Ir peak with a maximum abundance of 1566 $\pm 222 \mathrm{ppt}$ is observed in Core $15 \mathrm{X}$, Section 4, 39-40 cm. After rapidly dropping by a factor of four on either side in about 4 


\section{ODP 689B K-T Region}

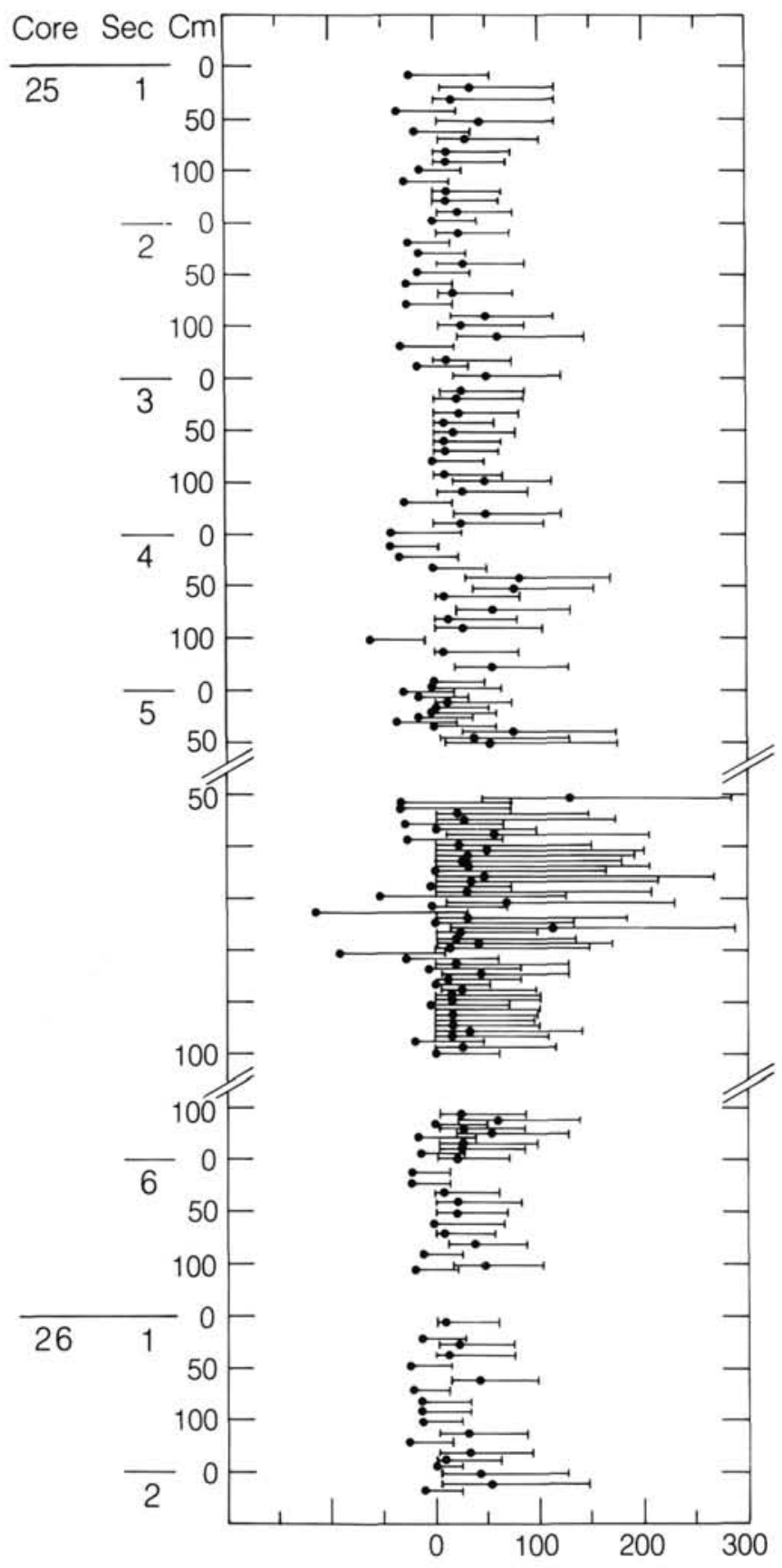

Whole-rock iridium abundance (ppt)

Figure 1. Iridium abundances in ODP Hole 689B Cretaceous-Tertiary boundary region.

$\mathrm{cm}$, the Ir abundance tails erratically and reaches background $72 \mathrm{~cm}$ upsection and $119 \mathrm{~cm}$ downsection. The K-T Ir anomaly can be detected over a stratigraphic span of about $2 \mathrm{~m}$.

The Ir peak occurs near the base of a dark layer in the sediment and tails upsection (in the dark layer) and downsection into the light-colored Cretaceous sediment. There are peaks in the $\mathrm{Ir}$ (and $\mathrm{Fe}$ ) abundance downsection which match blobs of dark material. The presence of $\mathrm{Al}$ and $\mathrm{Si}$ as well as $\mathrm{Fe}$ in the dark material suggests it is clay. From the X-ray fluorescence measurements, the Fe abundances below the $\mathrm{K}-\mathrm{T}$ peak are $4.6 \%$ of the noncalcareous masses. The average Fe abundance above and including the Ir peak region for 19 samples is $2.53 \%$ with a RMSD of $0.10 \%$. This Fe content would correspond to a noncalcareous content (mostly clay) of $55 \%$. The shipboard party reported that the core had extensive bioturbation and the Ir (and $\mathrm{Fe}$ ) peaks downsection may be the result of pushing of clay and Ir downward (e.g., 65-66 and 85-86 cm of Section 4, Core $15 \mathrm{X}$ ) or pulling up of $\mathrm{CaCO}_{3}$ (e.g., $40-41,42-44 \mathrm{~cm}$ in the same section) by large organisms with burrows of at least $40 \mathrm{~cm}$. In the K-T boundary section of DSDP Hole 577B (Michel et al., 1985), a mass of boundary material was identified about $40 \mathrm{~cm}$ below the K-T peak, which may also have been due to bioturbation by the same type of organism. By taking the ratio of Ir to clay (represented by the Ir:Fe ratio) the effect of pulling up of $\mathrm{CaCO}_{3}$ by biota can be essentially removed as well as any abundance variations due to changes in $\mathrm{CaCO}_{3}$ sedimentation rate. In addition, peaks of Ir downsection which are associated with peaks of clay would also be diminished. The Ir:Fe ratio (shown in Fig. 3) shows a peak at $38-41 \mathrm{~cm}$ and many of the peaks downsection have indeed been diminished. The existence of an $\mathrm{Ir} / \mathrm{Fe}$ peak instead of a plateau indicates the $\mathrm{Ir}$ is not associated with the clay, and also that the clay is present below the Ir. Since there is evidence for clay being moved downward by bioturbation, some of the clay directly below the Ir should be due to the same cause. The position of the $\mathrm{Ir} / \mathrm{Fe}$ peak $(38-41 \mathrm{~cm})$ with respect to the bottom of the $\mathrm{Fe}$ abundance plateau $(41-42 \mathrm{~cm}$ of Section 4, Core 15X) suggests the two events (Ir deposition and initial clay deposition) coincided stratigraphically within $2 \mathrm{~cm}$ of deposition and may have happened at the same time.

\section{Bioturbation and Volcanism}

The possibility that the Ir abundance pattern observed in the Cretaceous sediment of Section 4 could have been produced by moderate bioturbation by organisms with long burrows has already been discussed. The sharpness of the Ir peak and of the $\mathrm{Ir} / \mathrm{Fe}$ peak (particularly upsection) suggest that there was no intense bioturbation by small organisms. Otherwise, the peak would not have smoothly dropped by a factor of four in $4 \mathrm{~cm}$. If there were lenses of volcanic ash that altered to clay, bioturbation would not have spread the lenses to any greater degree than the Ir peak or Ir:Fe ratio and the lenses would need to be equally spaced by distances equivalent or smaller than the halfwidth (full width at half maximum) of the peaks, $\sim 6.6 \mathrm{~cm}$. Thus at least four nearly equally spaced lenses of comparable amounts of ash would be necessary to give the nearly constant clay abundance deduced for $19 \mathrm{~cm}$ of deposition starting with the Ir peak. This is possible but seems not very probable. As an alternative explanation, the calcite deposition rate may have dropped rather sharply in this region at about the time of the K$\mathrm{T}$ impact and reduced the sedimentation rate by a factor of $\sim 2.5$, remained fairly stable for $\sim 19 \mathrm{~cm}$ of deposition, and then slowly increased a factor of five over $\sim 80 \mathrm{~cm}$ of deposition. The decrease in $\mathrm{CaCO}_{3}$ deposition may have been triggered by the impact.

The radiation levels for the samples in the Cretaceous background region (for which only one $\mathrm{Fe}$ measurement was made) varied by a factor of two. Although in no way comparable to a direct measurement, the data suggest that the clay content may have been about $\sim 17 \%$ in the region of Section 6 from 31 to 91 $\mathrm{cm}$ with only a variation (RMSD) of $4 \%$ of the value. Therefore, prior to the K-T impact there is some evidence for sustained periods of enhanced clay deposition. The sedimentation system may have been precariously balanced and easily shifted by changes resulting from an impact. However, the onset of another period of enhanced clay deposition just at the time of the impact could also be a coincidence. Other workers (private 
H. V. MICHEL, F. ASARO, W. ALVAREZ, L. W. ALVAREZ

Table 1. Background iridium abundances in K-T region of ODP Hole 689B.

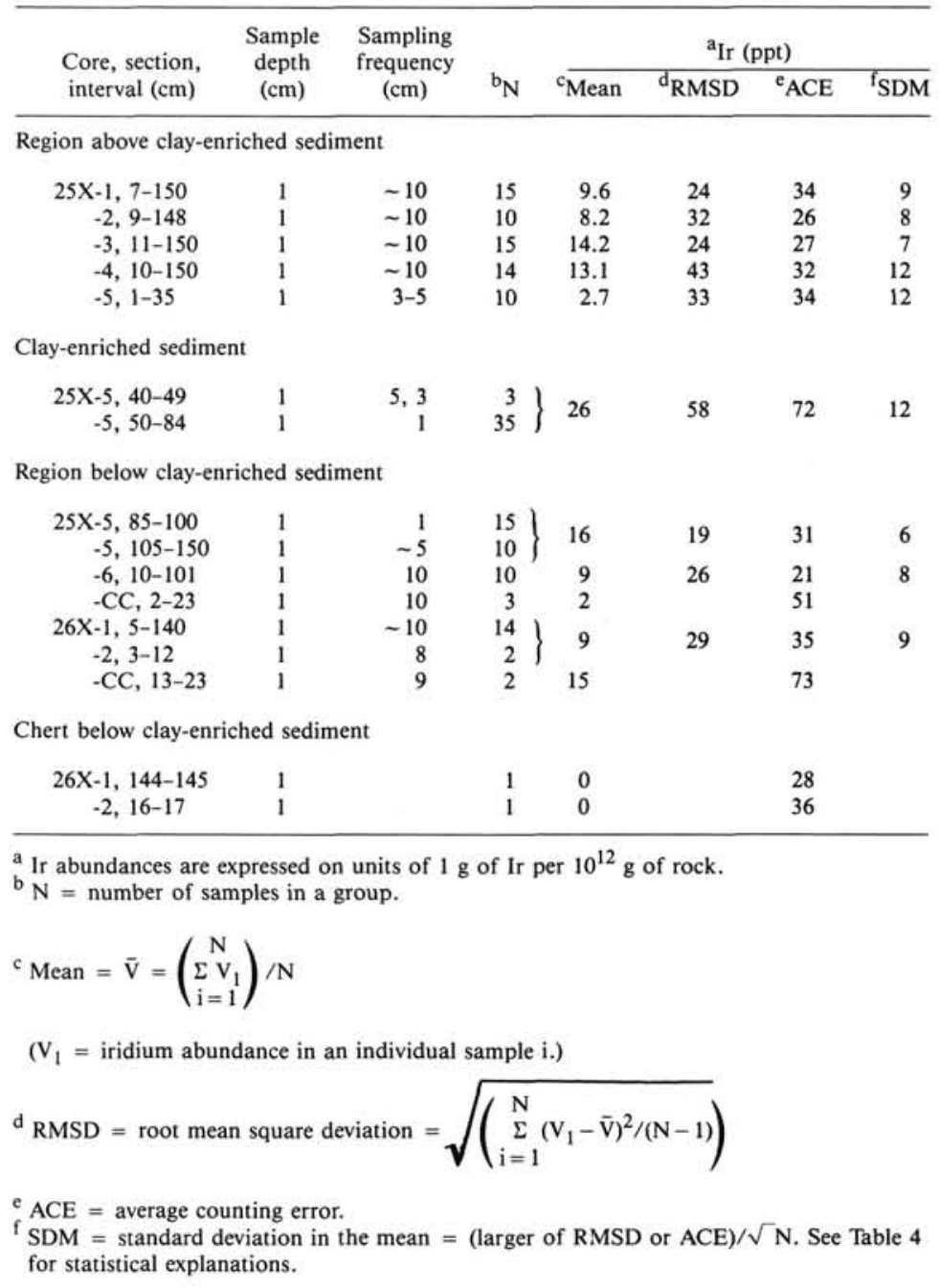

Table 2. Summary of iridium data in K-T region of ODP Hole 698B.

Best average of the Ir abundances:

$$
\begin{array}{ll}
\text { Above clay-enriched region } & \mathrm{Ir}=10.4 \pm 4.0 \mathrm{ppt} \\
\text { Clay-enriched region } & \mathrm{Ir}=25.6 \pm 11.6 \mathrm{ppt} \\
\text { Below clay-enriched region } & \mathrm{Ir}=12.6 \pm 4.3 \mathrm{ppt}
\end{array}
$$

The best average $\mathrm{Ir}$ abundances are the means (excluding chert and core catcher samples) weighted inversely by the squares of the standard deviation in the mean as given in Table 1. The error is the minimum (one sigma Gaussian) uncertainty in the best value if the Ir abundances within a group are constant.

$$
\begin{aligned}
& \text { Best average value }= \\
& \underset{\mathrm{J}=\mathrm{i}}{\sum_{\mathrm{N}} \text { Mean }_{\mathrm{j}} /\left(\mathrm{SDM}_{\mathrm{j}}\right)^{2} / \sum_{\mathrm{j}=\mathrm{i}}^{\mathrm{J}} \stackrel{1}{\left(\mathrm{SDM}_{\mathrm{j}}\right)^{2}}} \\
& \text { Best error }=\sqrt{1 / \sum_{\mathrm{j}=\mathrm{i}}^{\mathrm{J}} 1 /\left(\mathrm{SDM}_{\mathrm{j}}\right)^{2}} \\
& \mathrm{j}=\text { individual group identifier. } \\
& \mathrm{J}=\text { number of groups. }
\end{aligned}
$$

communication from J. Kennett) have found that the clay component near the Hole $690 \mathrm{C} \mathrm{K}-\mathrm{T}$ boundary had a dominant pedogenic origin.

\section{ACKNOWLEDGMENTS}

This work was supported by the Director, Office of Energy Research, Office of Basic Energy Sciences, Chemical Sciences Division, of the U.S. Department of Energy under Contract No. DE-ACO3-76SF00098. We also thank the National Aeronautics and Space Administration for their support under Contract No. A-59508C. The construction costs for the Iridium Coincidence Spectrometer were defrayed principally by the generosity of the Murdock Charitable Trust. We are very appreciative of grants by Dr. John Lawrence. Small grants were also received from the California Space Institute and the U.C. Berkeley Foundation. The computer system for the neutron activation data reduction was generously provided by the Hewlett Packard Company Foundation. The neutron irradiations were most efficiently provided by Martha Ann Carter, supervisor of the University of Missouri Research Reactor and her staff. We are indebted to Kristine Ing for preparation of the samples for irradiation and Linda Sindelar for preparation of samples and shepherding the sample flow to the reactor. 
Table 3. Abundances of elements other than iridium in selected parts of the K-T region of ODP Hole 689B.

\begin{tabular}{|c|c|c|c|c|c|}
\hline $\begin{array}{l}\text { Core, section, } \\
\text { interval }(\mathrm{cm})\end{array}$ & $\begin{array}{c}\text { Co } \\
\text { (ppm) }\end{array}$ & $\underset{(\mathrm{ppm})}{\mathrm{Cs}}$ & $\underset{(\mathrm{ppm})}{\mathrm{Eu}}$ & $\begin{array}{l}\mathrm{Fe} \\
(\%)\end{array}$ & $\underset{(\mathrm{ppm})}{\mathrm{Sc}}$ \\
\hline $25 X-4,70-71$ & $2.20 \pm 0.02$ & $0.163 \pm 0.009$ & $0.641 \pm 0.011$ & $0.33 \pm 0.02$ & $3.40 \pm 0.03$ \\
\hline $25 X-5,48-49$ & $3.69 \pm 0.04$ & $0.411 \pm 0.012$ & $1.097 \pm 0.017$ & $0.65 \pm 0.03$ & $6.22 \pm 0.06$ \\
\hline $61-62$ & $3.24 \pm 0.03$ & $0.285 \pm 0.012$ & $1.355 \pm 0.021$ & $0.61 \pm 0.03$ & $6.78 \pm 0.07$ \\
\hline $64-65$ & $3.77 \pm 0.04$ & $0.341 \pm 0.013$ & $1.630 \pm 0.024$ & $0.76 \pm 0.04$ & $7.81 \pm 0.08$ \\
\hline $69-70$ & $2.23 \pm 0.02$ & $0.327 \pm 0.012$ & $1.342 \pm 0.020$ & $0.68 \pm 0.04$ & $6.89 \pm 0.07$ \\
\hline $74-75$ & $2.19 \pm 0.02$ & $0.330 \pm 0.012$ & $1.241 \pm 0.018$ & $0.66 \pm 0.04$ & $6.17 \pm 0.06$ \\
\hline $79-80$ & $2.07 \pm 0.02$ & $0.340 \pm 0.011$ & $1.155 \pm 0.018$ & $0.61 \pm 0.04$ & $4.94 \pm 0.05$ \\
\hline $84-85$ & $1.48 \pm 0.02$ & $0.277 \pm 0.009$ & $0.997 \pm 0.016$ & $0.42 \pm 0.03$ & $4.05 \pm 0.04$ \\
\hline $144-145$ & $0.66 \pm 0.01$ & $0.147 \pm 0.008$ & $0.650 \pm 0.011$ & $0.18 \pm 0.02$ & $2.46 \pm 0.02$ \\
\hline
\end{tabular}

Errors are estimated one sigma values of the precision of measurement, not the accuracy. The accuracy is probably about $5 \%$.

\section{REFERENCES}

Alvarez, L. W., 1987a. Mass extinctions caused by large bolide impacts. Phys. Today, 40:24-33.

1987b. Experimental evidence that an Asteroid impact led to the extinction of many species 65 Million Years Ago, Proc. Natl. Acad. Sci., USA, 80:627-642.

Alvarez, W., Asaro, F., Michel, H. V., and Alvarez, L. W., 1982. Iridium anomaly approximately synchronous with terminal Eocene extinctions, Science, 216:886-888.

Asaro, F., Alvarez, L. W., Alvarez, W., and Michel, H. V., 1987. Operation of the Iridium Coincidence Spectrometer: Studies in the middle Miocene and near the Cenomanian-Turonian Boundary. Abstracts, IGCP, China., 199:65.

Asaro, F., Michel, H. V., Alvarez, L. W., Alvarez, W., and Montanari, A., 1988. Impacts and multiple Iridium Anomalies, EOS Abstr, 1530;U32A-5.

Barker, P. F., Kennett, J. P., et al., 1988. Proc. ODP, Init. Repts., 113: College Station, TX (Ocean Drilling Program).
Giauque, R. D., Goulding, F. S., Jaklevic, J. M., and Pehl, R. H., 1973. Trace element determinations with Semiconductor Detector Xray Spectrometers, Anal. Chem., 45:671-681.

Hebert, A. J., and Street, K., Jr., 1974. Nondispersive soft X-ray Fluorescence Spectrometer for quantitative analysis of major elements in rocks and minerals, Anal. Chem., 46:203-207.

Michel, H. V., Asaro, F., Alvarez, W., and Alvarez, L. W., 1985. Elemental profile of iridium and other elements near the Cretaceous/ Tertiary boundary in Hole 577B, In Heath, G. T., Burckle, L. H., et al., Init. Repts. DSDP, 86: Washington (U.S. Govt. Printing Office), 533-538.

Date of initial receipt: 30 January 1989

Date of acceptance: 15 June 1989

Ms 113B-161 


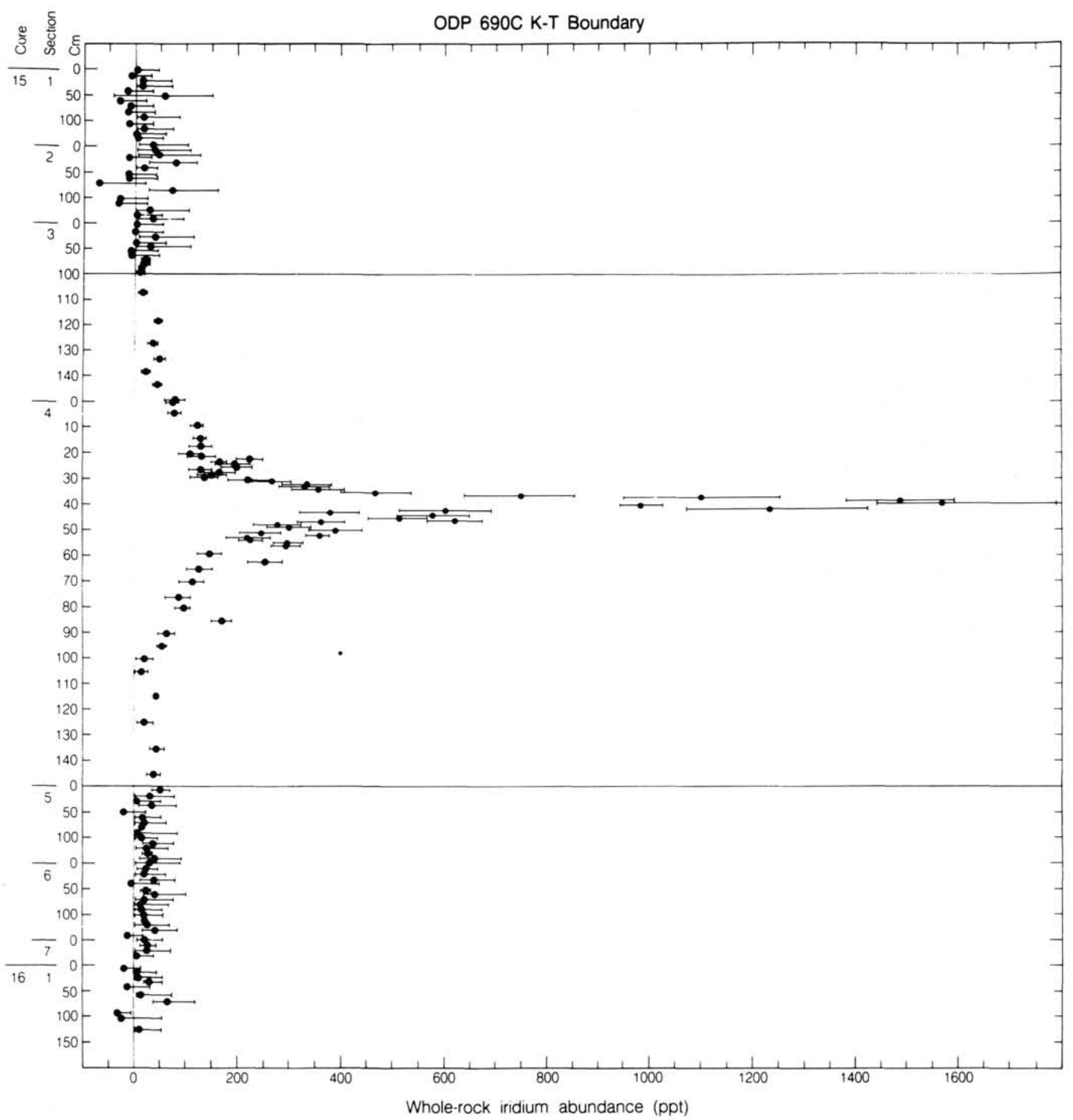

Figure 2. Iridium abundances in ODP Hole $690 \mathrm{C}$ Cretaceous-Tertiary boundary region. 


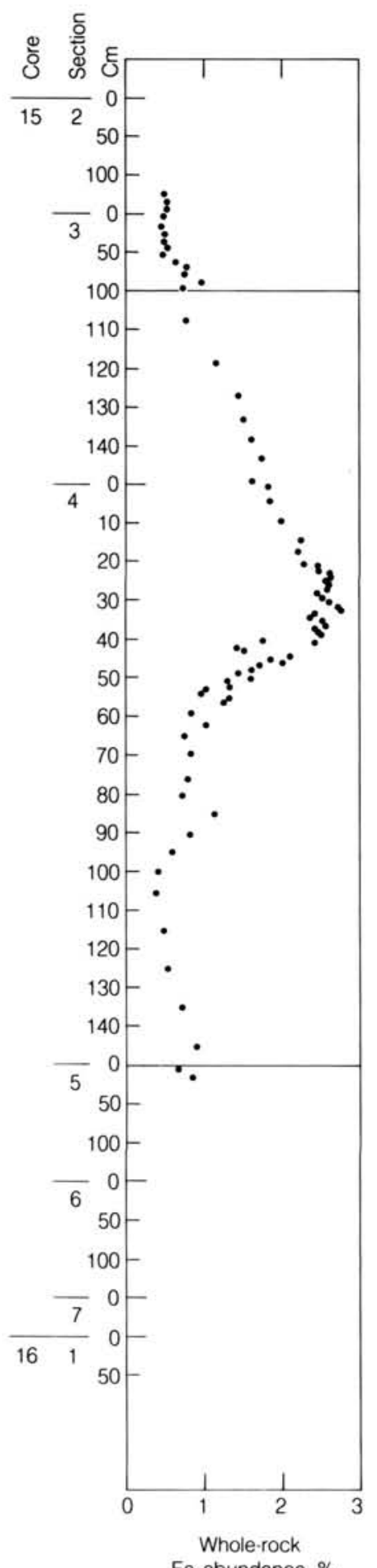

ODP 690C K-T Boundary
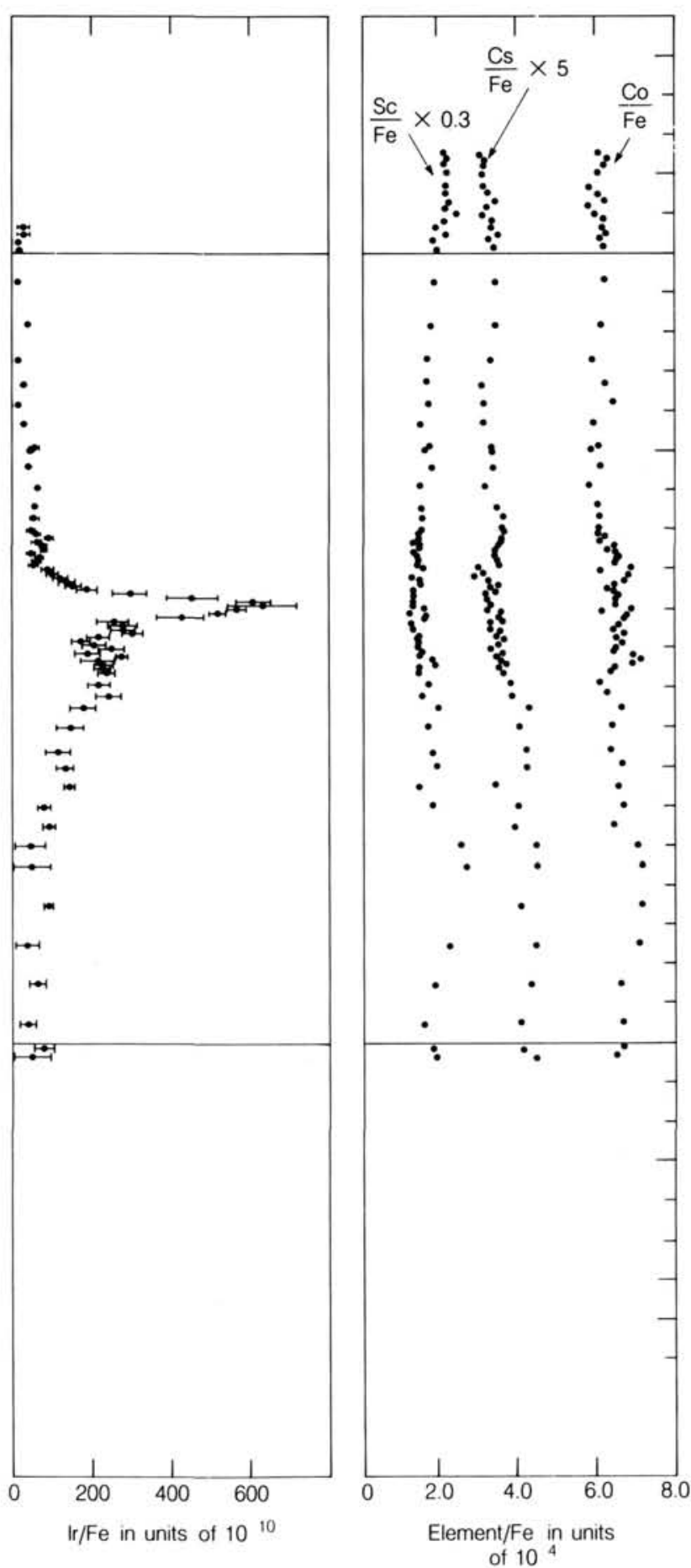

Figure 3. Fe abundances and ratios of abundances of Ir, Sc, Cs, and Co to those of Fe in the ODP Hole 690C Cretaceous-Tertiary boundary region. The ratios of $\mathrm{Sc} / \mathrm{Fe}$ and $\mathrm{Cs} / \mathrm{Fe}$ have been multiplied by 0.3 and 5 , respectively, to fit on the graph. 
Table 4. Iridium abundances in region around K-T boundary of ODP Hole 690C.

\begin{tabular}{|c|c|c|c|c|c|c|c|}
\hline \multirow{2}{*}{$\begin{array}{l}\text { Core, section, } \\
\text { interval }(\mathrm{cm})\end{array}$} & \multirow{2}{*}{$\begin{array}{l}\text { Sample } \\
\text { depth } \\
(\mathrm{cm})\end{array}$} & \multirow{2}{*}{$\begin{array}{l}\text { Sampling } \\
\text { frequency } \\
\text { (cm) }\end{array}$} & \multirow[b]{2}{*}{$\mathrm{N}$} & \multicolumn{4}{|c|}{${ }^{\mathrm{a}} \mathrm{Ir}(\mathrm{ppt})$} \\
\hline & & & & Mean & RMSD & ACE & SDM \\
\hline
\end{tabular}

Low-precision measurements above K-T boundary (7-min scans)

\begin{tabular}{|c|c|c|c|c|c|c|}
\hline $15 X-1,1-148$ & 1 & $\sim 10$ & 15 & & & \\
\hline$-2,7-143$ & 1 & $\sim 10$ & $14\}$ & 4 & 31 & 24 \\
\hline$-3,2-64$ & 1 & $\sim 10$ & 7 J & & . & \\
\hline
\end{tabular}

Higher precision measurements

\begin{tabular}{|c|c|c|c|c|c|c|c|}
\hline $15 X-3,71-108$ & 1 & $\sim 10$ & 5 & 14.6 & 5 & 8 & 3.4 \\
\hline$-3,118-144$ & 1 & -6 & 5 & 36 & 13 & 9 & 6 \\
\hline$-3,149-150$ & 1 & & 1) & & & & \\
\hline$-4,0-5$ & 1 & 4 & $2\}$ & 75 & 2 & 14 & 8 \\
\hline$-4,9-22$ & 1 & $5,3,3,1$ & 5) & & & & \\
\hline
\end{tabular}

K-T boundary interval

Low-precision measurements below K-T boundary (14-min scans)

\begin{tabular}{|c|c|c|c|c|c|c|c|}
\hline $15 X-5,18-150$ & 1 & $\sim 10$ & 14 & 22 & 19 & 30 & 8 \\
\hline$-6,10-150$ & 1 & -10 & 15 & 25 & 24 & 38 & 10 \\
\hline$-7,10-31$ & 1 & 10 & 3 & 11 & 33 & 34 & 10 \\
\hline $16 \times-1,6-128$ & 1 & -10 & 10 & 11 & 33 & 34 & 10 \\
\hline $15 X-C C, 5-26$ & 1 & 10 & 3 & 27 & & 39 & \\
\hline
\end{tabular}

Higher precision measurements

$\begin{array}{cccc}15 X-5,79-80 & 1 & 1 & 13.9 \pm 4.9 \\ -5,130-131 & 1 & 1 & 20.8 \pm 7.0 \\ -6,10-11 & 1 & 1 & 19 \pm 25 \\ -6,50-51 & 1 & 1 & 17 \pm 5 \\ -6,110-111 & 1 & 1 & 21 \pm 19 \\ -7,10-11 & 1 & 1 & 26 \pm 28 \\ -C C, 25-26 & 1 & & \\ & & 1 & 29+21 \\ & & & \end{array}$

${ }^{\text {a }}$ Ir abundances are expressed in units of $1 \mathrm{~g}$ of $\mathrm{Ir}$ per $10^{12} \mathrm{~g}$ of rock. When errors are symmetrical (for single samples) or when both the RMSD and ACE are listed, Gaussian statistics were used. When errors are asymmetrical (for single sample) or when only the ACE is listed, Poisson statistics were used and the ACE refers only to the upper limit. See Table 1 for definition of terms.

Table 5. Background abundance of iridium in ODP Hole 690C.

Above K-T boundary

Low precision scan

Best average value of $\mathrm{Ir}=4.0 \pm 5.1 \mathrm{ppt}$

Below K-T boundary

Low precision scan

Best average value of $\mathrm{Ir}=19.7 \pm 5.2 \mathrm{ppt}$

Higher precision runs

Best average value of $\mathrm{Ir}=17.2 \pm 2.8 \mathrm{ppt}$

Overall

Best average value $=17.8 \pm 2.5 \mathrm{ppt}$ 
Table 6. Abundances of elements in K-T region of ODP Hole 690C, Core 15X, Sections 3, 4, and 5.

\begin{tabular}{|c|c|c|c|c|c|c|c|c|c|c|c|c|c|}
\hline Sample & $\underset{\text { (ppt) }}{\text { Ir }}$ & $\begin{array}{c}\text { Co } \\
\text { (ppm) }\end{array}$ & $\begin{array}{c}\mathrm{Sc} \\
(\mathrm{ppm})\end{array}$ & $\begin{array}{l}\mathrm{Fe} \\
\%\end{array}$ & $\begin{array}{c}\mathrm{Cs} \\
\text { (ppm) }\end{array}$ & $\begin{array}{c}\mathrm{Cr} \\
\text { (ppm) }\end{array}$ & $\begin{array}{c}\text { Th } \\
\text { (ppm) }\end{array}$ & $\begin{array}{c}\mathrm{Tb} \\
\text { (ppm) }\end{array}$ & $\begin{array}{c}\mathrm{Zn} \\
\text { (ppm) }\end{array}$ & $\begin{array}{c}\text { Eu } \\
(\mathrm{ppm})\end{array}$ & $\begin{array}{c}\mathrm{Ce} \\
(\mathrm{ppm})\end{array}$ & $\begin{array}{c}\text { Hf } \\
(\mathrm{ppm})\end{array}$ & $\begin{array}{c}\mathrm{Yb} \\
\text { (ppm) }\end{array}$ \\
\hline $690 \mathrm{C}-15 \mathrm{X}-3,149-150$ & $77 \pm 20$ & 9.64 & 9.29 & $1.61 \pm 0.02$ & $1.05 \pm 0.02$ & $<7.7$ & $5.03 \pm 0.26$ & $0.755 \pm 0.022$ & $90.7 \pm 0.9$ & 1.186 & $48.40 \pm 1.15$ & $0.95 \pm 0.04$ & $2.333 \pm 0.076$ \\
\hline $690 C-15 X-4,0-1$ & $73 \pm 12$ & 10.63 & 9.98 & $1.83 \pm 0.02$ & $1.19 \pm 0.02$ & $<8.1$ & $5.82 \pm 0.28$ & $0.906 \pm 0.025$ & $95.3 \pm 1.0$ & 1.242 & $51.59 \pm 1.23$ & $0.81 \pm 0.05$ & $2.707 \pm 0.082$ \\
\hline $690 \mathrm{C}-15 X-4,4-5$ & $76 \pm 11$ & 11.15 & 10.78 & $1.84 \pm 0.02$ & $1.23 \pm 0.02$ & $6.9 \pm 2.3$ & $6.23 \pm 0.29$ & $0.873 \pm 0.025$ & $107.2 \pm 1.1$ & 1.366 & $53.93 \pm 1.26$ & $1.11 \pm 0.05$ & $2.682 \pm 0.083$ \\
\hline $690 C-15 X-4,9-10$ & $119 \pm 12$ & 11.05 & 9.50 & $1.94 \pm 0.02$ & $1.21 \pm 0.02$ & $4.3 \pm 2.1$ & $6.10 \pm 0.27$ & $0.807 \pm 0.023$ & $91.6 \pm 0.9$ & 1.309 & $55.47 \pm 1.24$ & $1.06 \pm 0.05$ & $2.454 \pm 0.079$ \\
\hline $690 \mathrm{C}-15 \mathrm{X}-4,14-15$ & $125 \pm 12$ & 13.59 & 11.66 & $2.29 \pm 0.02$ & $1.58 \pm 0.02$ & $6.7 \pm 2.4$ & $7.13 \pm 0.30$ & $0.910 \pm 0.026$ & $122.5 \pm 1.2$ & 1.448 & $58.00 \pm 1.34$ & $1.41 \pm 0.05$ & $2.981 \pm 0.087$ \\
\hline $690 \mathrm{C}-15 \mathrm{X}-4,17-18$ & $127 \pm 22$ & 13.33 & 11.19 & $2.21 \pm 0.02$ & $1.57 \pm 0.02$ & $<7.6$ & $7.02 \pm 0.30$ & $0.878 \pm 0.025$ & $117.1 \pm 1.2$ & 1.441 & $58.04 \pm 1.32$ & $1.44 \pm 0.05$ & $2.821 \pm 0.086$ \\
\hline $690 \mathrm{C}-15 \mathrm{X}-4,20-21$ & $105 \pm 21$ & 13.60 & 11.39 & $2.27 \pm 0.02$ & $1.61 \pm 0.02$ & $8.1 \pm 2.4$ & $7.32 \pm 0.30$ & $0.952 \pm 0.027$ & $121.7 \pm 1.2$ & 1.435 & $55.29 \pm 1.32$ & $1.44 \pm 0.05$ & $2.757 \pm 0.085$ \\
\hline $690 \mathrm{C}-15 \mathrm{X}-4,21-22$ & $128 \pm 27$ & 14.66 & 11.67 & $2.45 \pm 0.02$ & $1.75 \pm 0.02$ & $8.7 \pm 2.4$ & $7.80 \pm 0.31$ & $0.943 \pm 0.026$ & $126.7 \pm 1.3$ & 1.539 & $64.13 \pm 1.39$ & $1.60 \pm 0.05$ & $2.793 \pm 0.087$ \\
\hline $690 C-15 X-4,22-23$ & $221 \pm 26$ & 15.03 & 11.60 & $2.45 \pm 0.02$ & $1.72 \pm 0.02$ & $<8.4$ & $7.19 \pm 0.31$ & $0.892 \pm 0.026$ & $128.0 \pm 1.3$ & 1.459 & $58.32 \pm 1.36$ & $1.67 \pm 0.05$ & $2.676 \pm 0.086$ \\
\hline $690 C-15 X-4,23-24$ & $163 \pm 15$ & 15.85 & 11.46 & $2.62 \pm 0.03$ & $1.83 \pm 0.02$ & $<8.5$ & $7.97 \pm 0.32$ & $0.959 \pm 0.027$ & $138.4 \pm 1.4$ & 1.524 & $62.47 \pm 1.39$ & $1.73 \pm 0.05$ & $2.937 \pm 0.089$ \\
\hline $690 \mathrm{C}-15 \mathrm{X}-4,24-25$ & $190 \pm 34$ & 16.59 & 12.59 & $2.59 \pm 0.03$ & $1.78 \pm 0.02$ & $5.2 \pm 2.5$ & $8.17 \pm 0.32$ & $0.871 \pm 0.025$ & $147.6 \pm 1.5$ & 1.441 & $59.77 \pm 1.39$ & $1.84 \pm 0.06$ & $2.773 \pm 0.088$ \\
\hline $690 \mathrm{C}-15 \mathrm{X}-4,25-26$ & $197 \pm 30$ & 16.32 & 12.29 & $2.54 \pm 0.03$ & $1.73 \pm 0.02$ & $<8.7$ & $7.72 \pm 0.32$ & $0.927 \pm 0.026$ & $145.7 \pm 1.6$ & 1.474 & $59.82 \pm 1.40$ & $1.79 \pm 0.06$ & $2.754 \pm 0.088$ \\
\hline $690 \mathrm{C}-15 \mathrm{X}-4,26-27$ & $126 \pm 22$ & 16.17 & 11.77 & $2.60 \pm 0.03$ & $1.76 \pm 0.02$ & $6.7 \pm 2.5$ & $8.15 \pm 0.32$ & $0.966 \pm 0.027$ & $137.7 \pm 1.4$ & 1.565 & $61.01 \pm 1.41$ & $1.86 \pm 0.06$ & $2.793 \pm 0.088$ \\
\hline $690 \mathrm{C}-15 \mathrm{X}-4,27-28$ & $164 \pm 31$ & 16.59 & 12.12 & $2.57 \pm 0.03$ & $1.74 \pm 0.02$ & $7.2 \pm 2.5$ & $8.40 \pm 0.32$ & $0.898 \pm 0.026$ & $142.5 \pm 1.4$ & 1.476 & $57.60 \pm 1.38$ & $1.77 \pm 0.06$ & $2.570 \pm 0.087$ \\
\hline $690 \mathrm{C}-15 \mathrm{X}-4,28-29$ & $150 \pm 29$ & 15.66 & 11.76 & $2.47 \pm 0.02$ & $1.71 \pm 0.02$ & $<9.8$ & $7.54 \pm 0.31$ & $0.943 \pm 0.027$ & $134.9 \pm 1.3$ & 1.521 & $60.98 \pm 1.39$ & $1.86 \pm 0.06$ & $2.578 \pm 0.086$ \\
\hline $690 \mathrm{C}-15 \mathrm{X}-4,29-30$ & $134 \pm 27$ & 15.68 & 11.80 & $2.52 \pm 0.03$ & $1.74 \pm 0.02$ & $<9.9$ & $7.61 \pm 0.32$ & $0.981 \pm 0.027$ & $132.2 \pm 1.3$ & 1.553 & $62.39 \pm 1.40$ & $1.72 \pm 0.06$ & $2.718 \pm 0.088$ \\
\hline $690 \mathrm{C}-15 \mathrm{X}-4,30-31$ & $223 \pm 42$ & 17.39 & 12.98 & $2.62 \pm 0.03$ & $1.56 \pm 0.02$ & $<9.5$ & $7.16 \pm 0.33$ & $0.882 \pm 0.026$ & $151.4 \pm 1.5$ & 1.391 & $55.91 \pm 1.38$ & $1.77 \pm 0.06$ & $2.457 \pm 0.086$ \\
\hline $690 \mathrm{C}-15 \mathrm{X}-4,31-32$ & $264 \pm 39$ & 17.32 & 12.46 & $2.70 \pm 0.03$ & $1.64 \pm 0.02$ & & $7.42 \pm 0.32$ & $0.866 \pm 0.025$ & $177.1 \pm 1.8$ & 1.435 & $55.56 \pm 1.39$ & $1.74 \pm 0.06$ & $2.384 \pm 0.036$ \\
\hline $690 \mathrm{C}-15 \mathrm{X}-4,32-33$ & $333 \pm 49$ & 17.54 & 11.96 & $2.77 \pm 0.03$ & $1.59 \pm 0.02$ & $<8.8$ & $7.73 \pm 0.32$ & $0.813 \pm 0.024$ & $173.6 \pm 1.7$ & 1.367 & $55.27 \pm 1.35$ & $1.70 \pm 0.05$ & $2.325 \pm 0.083$ \\
\hline $690 \mathrm{C}-15 \mathrm{X}-4,33-34$ & $328 \pm 50$ & 15.29 & 11.51 & $2.40 \pm 0.02$ & $1.53 \pm 0.02$ & $8.1 \pm 2.5$ & $6.34 \pm 0.31$ & $0.931 \pm 0.026$ & $138.3 \pm 1.4$ & 1.498 & $57.57 \pm 1.36$ & $1.56 \pm 0.05$ & $1.583 \pm 0.086$ \\
\hline $690 \mathrm{C}-15 \mathrm{X}-4,34-35$ & $355 \pm 52$ & 15.06 & 11.29 & $2.36 \pm 0.02$ & $1.62 \pm 0.02$ & $14.7 \pm 2.3$ & $6.90 \pm 0.29$ & $0.869 \pm 0.025$ & $134.5 \pm 1.3$ & 1.440 & $53.69 \pm 1.26$ & $1.51 \pm 0.05$ & $2.526 \pm 0.080$ \\
\hline $690 \mathrm{C}-15 \mathrm{X}-4,35-36$ & $467 \pm 68$ & 15.67 & 11.10 & $2.52 \pm 0.03$ & $1.63 \pm 0.02$ & $5.8 \pm 2.2$ & $6.81 \pm 0.29$ & $0.881 \pm 0.025$ & $133.5 \pm 1.3$ & 1.429 & $52.66 \pm 1.25$ & $1.41 \pm 0.05$ & $1.493 \pm 0.079$ \\
\hline $690 \mathrm{C}-15 \times-4,36-37$ & $747 \pm 108$ & 16.16 & 11.29 & $2.53 \pm 0.03$ & $1.70 \pm 0.02$ & $7.5 \pm 2.3$ & $7.32 \pm 0.29$ & $0.874 \pm 0.025$ & $135.5 \pm 1.4$ & 1.446 & $55.59 \pm 1.27$ & $1.54 \pm 0.05$ & $2.373 \pm 0.079$ \\
\hline $690 \mathrm{C}-15 \mathrm{X}-4,37-38$ & $1101 \pm 154$ & 15.61 & 10.61 & $2.42 \pm 0.02$ & $1.52 \pm 0.02$ & $8.2 \pm 2.2$ & $6.72 \pm 0.28$ & $0.863 \pm 0.025$ & $128.6 \pm 1.3$ & 1.370 & $52.37 \pm 1.23$ & $1.35 \pm 0.05$ & $2.279 \pm 0.077$ \\
\hline $690 \mathrm{C}-15 \mathrm{X}-4,38-39$ & $1487 \pm 105$ & 15.74 & 10.51 & $2.45 \pm 0.02$ & $1.56 \pm 0.02$ & $7.4 \pm 2.2$ & $6.51 \pm 0.28$ & $0.841 \pm 0.024$ & $128.3 \pm 1.3$ & 1.398 & $52.62 \pm 1.23$ & $1.36 \pm 0.05$ & $2.333 \pm 0.078$ \\
\hline $690 \mathrm{C}-15 \mathrm{X}-4,39-40$ & $1566 \pm 222$ & 15.90 & 10.79 & $2.49 \pm 0.02$ & $1.63 \pm 0.02$ & $5.0 \pm 2.2$ & $6.93 \pm 0.29$ & $0.863 \pm 0.025$ & $131.5 \pm 1.3$ & 1.426 & $53.01 \pm 1.24$ & $1.52 \pm 0.05$ & $2.305 \pm 0.077$ \\
\hline $690 \mathrm{C}-15 \mathrm{X}-4,40-41$ & $983 \pm 43$ & 11.79 & 9.03 & $1.74 \pm 0.02$ & $1.12 \pm 0.02$ & $10.9 \pm 2.0$ & $4.78 \pm 0.25$ & $0.740 \pm 0.021$ & $105.0 \pm 1.1$ & 1.165 & $42.84 \pm 1.09$ & $0.99 \pm 0.04$ & $2.128 \pm 0.071$ \\
\hline $690 C-15 X-4,41-42$ & $1237 \pm 55$ & 14.55 & 9.51 & $2.40 \pm 0.02$ & $1.69 \pm 0.02$ & $12.1 \pm 2.2$ & $7.00 \pm 0.27$ & $0.883 \pm 0.025$ & $111.1 \pm 1.1$ & 1.456 & $55.14 \pm 1.23$ & $1.34 \pm 0.05$ & $2.527 \pm 0.078$ \\
\hline $690 C-15 X-4,42-43$ & $602 \pm 90$ & 9.62 & 7.67 & $1.44 \pm 0.01$ & $1.00 \pm 0.02$ & $<6.6$ & $4.16 \pm 0.24$ & $0.689 \pm 0.020$ & $87.8 \pm 0.9$ & 1.107 & $39.89 \pm 1.03$ & $0.81 \pm 0.04$ & $2.112 \pm 0.069$ \\
\hline $690 \mathrm{C}-15 \mathrm{X}-4,43-44$ & $378 \pm 59$ & 10.01 & 7.80 & $1.51 \pm 0.02$ & $1.07 \pm 0.02$ & $<7.2$ & $4.38 \pm 0.24$ & $0.727 \pm 0.021$ & $89.1 \pm 0.9$ & 1.173 & $43.05 \pm 1.06$ & $0.91 \pm 0.04$ & $2.184 \pm 0.071$ \\
\hline $690 \mathrm{C}-15 \mathrm{X}-4,44-45$ & $578 \pm 72$ & 13.79 & 8.60 & $2.12 \pm 0.02$ & $1.37 \pm 0.02$ & $6.5 \pm 2.1$ & $6.88 \pm 0.26$ & $0.753 \pm 0.022$ & $109.3 \pm 1.1$ & 1.191 & $44.85 \pm 1.13$ & $1.35 \pm 0.05$ & $1.933 \pm 0.071$ \\
\hline $690 C-15 X-4,45-46$ & $511 \pm 57$ & 11.92 & 7.84 & $1.84 \pm 0.02$ & $1.19 \pm 0.02$ & $6.3 \pm 2.0$ & $5.29 \pm 0.25$ & $0.764 \pm 0.022$ & $101.5 \pm 1.0$ & 1.228 & $42.60 \pm 1.10$ & $0.94 \pm 0.04$ & $2.101 \pm 0.072$ \\
\hline $690 C-15 X-4,46-47$ & $619 \pm 56$ & 13.08 & 8.86 & $2.06 \pm 0.02$ & $1.42 \pm 0.02$ & $6.9 \pm 2.1$ & $6.13 \pm 0.26$ & $0.801 \pm 0.023$ & $104.3 \pm 1.0$ & 1.315 & $48.66 \pm 1.16$ & $1.20 \pm 0.05$ & $2.292 \pm 0.075$ \\
\hline $690 C-15 X-4,47-48$ & $362 \pm 47$ & 11.14 & 8.05 & $1.70 \pm 0.02$ & $1.15 \pm 0.02$ & $5.5 \pm 2.0$ & $5.10 \pm 0.25$ & $0.766 \pm 0.022$ & $93.8 \pm 0.9$ & 1.235 & $43.92 \pm 1.09$ & $1.04 \pm 0.04$ & $2.164 \pm 0.072$ \\
\hline $690 \mathrm{C}-15 \mathrm{X}-4,48-49$ & $276 \pm 48$ & 10.43 & 7.49 & $1.62 \pm 0.02$ & $1.16 \pm 0.02$ & $5.9 \pm 1.9$ & $5.26 \pm 0.24$ & $0.742 \pm 0.021$ & $86.7 \pm 0.9$ & 1.157 & $42.77 \pm 1.05$ & $0.93 \pm 0.04$ & $2.078 \pm 0.069$ \\
\hline $690 C-15 X-4,49-50$ & $298 \pm 44$ & 9.61 & 7.05 & $1.46 \pm 0.01$ & $0.99 \pm 0.02$ & $<6.6$ & $4.70 \pm 0.23$ & $0.690 \pm 0.020$ & $80.8 \pm 0.8$ & 1.121 & $38.92 \pm 1.02$ & $0.96 \pm 0.04$ & $1.957 \pm 0.068$ \\
\hline $690 C-15 X-4,50-51$ & $389 \pm 53$ & 10.18 & 7.39 & $1.58 \pm 0.02$ & $1.03 \pm 0.02$ & $6.7 \pm 1.9$ & $4.92 \pm 0.24$ & $0.675 \pm 0.020$ & $87.0 \pm 0.9$ & 1.113 & $40.07 \pm 1.03$ & $0.96 \pm 0.04$ & $2.012 \pm 0.068$ \\
\hline $690 C-15 X-4,51-52$ & $248 \pm 41$ & 8.15 & 6.48 & $1.29 \pm 0.01$ & $0.92 \pm 0.02$ & $4.3 \pm 1.8$ & $3.97 \pm 0.22$ & $0.665 \pm 0.019$ & $74.7 \pm 0.7$ & 1.080 & $36.33 \pm 0.98$ & $0.78 \pm 0.04$ & $2.035 \pm 0.067$ \\
\hline $690 \mathrm{C}-15 \mathrm{X}-4,52-53$ & $361 \pm 20$ & 8.97 & 6.52 & $1.32 \pm 0.01$ & $0.91 \pm 0.02$ & $<4.7$ & $3.97 \pm 0.23$ & $0.730 \pm 0.020$ & $77.5 \pm 0.8$ & 1.176 & $40.21 \pm 1.01$ & $0.74 \pm 0.04$ & $2.008 \pm 0.068$ \\
\hline $690 \mathrm{C}-15 \mathrm{X}-4,53-54$ & $218 \pm 43$ & 7.26 & 6.15 & $1.03 \pm 0.01$ & $0.72 \pm 0.02$ & $<3.6$ & $3.06 \pm 0.21$ & $0.617 \pm 0.018$ & $69.7 \pm 0.7$ & 0.978 & $33.05 \pm 0.93$ & $0.66 \pm 0.04$ & $1.906 \pm 0.065$ \\
\hline
\end{tabular}


Table 6 (Continued).

$690 \mathrm{C}-15 \mathrm{X}-4,54-55$ $690 \mathrm{C}-15 \times-4,55-56$ $690 \mathrm{C}-15 \times-4,56-57$ $690 \mathrm{C}-15 \times-4,59-60$ $690 \mathrm{C}-15 \mathrm{X}-4,62-63$ 690C-15X-4, 65-66 $690 \mathrm{C}-15 \mathrm{X}-4,70-7$ $690 \mathrm{C}-15 \mathrm{X}-4,76-77$ $690 \mathrm{C}-15 \mathrm{X}-4,80-81$ $690 \mathrm{C}-15 \mathrm{X}-4,85-86$ 690C-15X-4, 90-91 $690 \mathrm{C}-15 \mathrm{X}-4,95-96$ $690 \mathrm{C}-15 \mathrm{X}-4,100-101$ $690 \mathrm{C}-15 \mathrm{X}-4,105-106$ $690 \mathrm{C}-15 \mathrm{X}-4,115-116$ $690 \mathrm{C}-15 \mathrm{X}-4,125-126$ $690 \mathrm{C}-15 \mathrm{X}-4,135-136$ $690 \mathrm{C}-15 \mathrm{X}-4,145-146$ 6CDC-15X-5, 8-9 69) - $15 X-5,18-19$ 690C-15X-5, 28-29 690C-15X-5, 39-40 $690 C-15 X-5,51-52$ $690 \mathrm{C}-15 \mathrm{X}-5,71-72$ $690 \mathrm{C}-15 \mathrm{X}-5,79-80$ $690 \mathrm{C}-15 \mathrm{X}-5,93-94$ 690C-15X-5, 102-103 690C-15X-5, 112-113 $690 \mathrm{C}-15 \mathrm{X}-5,120-121$ 690C-15X-5, 130-131 $690 \mathrm{C}-15 \mathrm{X}-5,140-141$ 690C-15X-5, 149-150 690C-15X-5, 10-11 $690 \mathrm{C}-15 \mathrm{X}-5,20-21$ $690 \mathrm{C}-15 \mathrm{X}-5,31-32$ $690 \mathrm{C}-15 \mathrm{X}-5,40-41$ 690C-15X-5, 60-61 $690 C-15 X-5,70-71$

\begin{tabular}{|c|c|}
\hline $223 \pm 23$ & 6.66 \\
\hline $297 \pm 29$ & 8.43 \\
\hline $292 \pm 29$ & 7.98 \\
\hline $174 \pm 23$ & 4.92 \\
\hline $252 \pm 33$ & 6.31 \\
\hline $126 \pm 24$ & 4.76 \\
\hline $111 \pm 23$ & 5.15 \\
\hline $84 \pm 23$ & 4.72 \\
\hline $93 \pm 15$ & 4.63 \\
\hline $162 \pm 15$ & 7.28 \\
\hline $62 \pm 16$ & 5.17 \\
\hline $52 \pm 8$ & 3.54 \\
\hline $4(+19,-13.6)$ & 2.80 \\
\hline $9(+24,-9)$ & 2.46 \\
\hline $43 \pm 5$ & 3.42 \\
\hline $6(+17,-12)$ & 3.52 \\
\hline $41 \pm 14$ & 4.62 \\
\hline $44(+15,-12)$ & 5.79 \\
\hline $8(+18,-14)$ & 4.17 \\
\hline $27(+49,-27)$ & 5.30 \\
\hline $2(+45,-2)$ & 5.39 \\
\hline $3(+47,-26)$ & 5.28 \\
\hline $19(+37,-19)$ & 7.12 \\
\hline $14(+35,-14)$ & 3.34 \\
\hline $7(+42,-17)$ & 4.71 \\
\hline $14 \pm 5$ & 3.76 \\
\hline $1(+31,-1)$ & 3.54 \\
\hline $2(+30,-12)$ & 2.32 \\
\hline $35(+40,-22)$ & 3.12 \\
\hline $23(+41,-23)$ & 3.57 \\
\hline $21 \pm 7$ & 6.35 \\
\hline $37(+53,-30)$ & 5.28 \\
\hline $30(+56,-25)$ & 5.34 \\
\hline $19(+25,-17)$ & 5.90 \\
\hline $16(+41,-16)$ & 5.68 \\
\hline $37(+39,-28)$ & 5.67 \\
\hline $7(+53,-7)$ & 5.02 \\
\hline $12(+55,-27)$ & 5.91 \\
\hline$(+53,-21)$ & 6.50 \\
\hline
\end{tabular}

$\begin{array}{lll}5.90 & 0.97 \pm 0.01 & 0.70 \pm 0.02 \\ 6.30 & 1.33 \pm 0.01 & 0.92 \pm 0.02 \\ 6.04 & 1.27 \pm 0.01 & 0.91 \pm 0.02 \\ 4.58 & 0.81 \pm 0.01 & 0.60 \pm 0.01 \\ 4.98 & 1.03 \pm 0.01 & 0.78 \pm 0.01 \\ 4.54 & 0.73 \pm 0.01 & 0.62 \pm 0.01 \\ 4.48 & 0.82 \pm 0.01 & 0.65 \pm 0.01 \\ 4.41 & 0.75 \pm 0.01 & 0.62 \pm 0.01 \\ 4.41 & 0.71 \pm 0.01 & 0.59 \pm 0.01 \\ 5.39 & 1.14 \pm 0.01 & 0.77 \pm 0.02 \\ 4.69 & 0.79 \pm 0.01 & 0.61 \pm 0.01 \\ 3.83 & 0.56 \pm 0.01 & 0.43 \pm 0.01 \\ 3.37 & 0.41 \pm 0.01 & 0.35 \pm 0.01 \\ 3.05 & 0.35 \pm 0.01 & 0.30 \pm 0.01 \\ 3.50 & 0.48 \pm 0.01 & 0.39 \pm 0.01 \\ 3.64 & 0.51 \pm 0.01 & 0.44 \pm 0.01 \\ 4.24 & 0.71 \pm 0.01 & 0.60 \pm 0.01 \\ 4.53 & 0.89 \pm 0.01 & 0.70 \pm 0.01 \\ 3.76 & 0.64 \pm 0.01 & 0.51 \pm 0.01 \\ 4.85 & 0.83 \pm 0.01 & 0.72 \pm 0.01 \\ 5.17 & 0.90 \pm 0.03 & 0.69 \pm 0.02 \\ 4.85 & 0.85 \pm 0.03 & 0.67 \pm 0.02 \\ 5.69 & 1.13 \pm 0.03 & 0.93 \pm 0.02 \\ 3.66 & 0.54 \pm 0.02 & 0.44 \pm 0.01 \\ 4.43 & 0.80 \pm 0.03 & 0.61 \pm 0.02 \\ 3.88 & 0.63 \pm 0.03 & 0.49 \pm 0.01 \\ 3.35 & 0.60 \pm 0.02 & 0.48 \pm 0.01 \\ 2.89 & 0.35 \pm 0.02 & 0.31 \pm 0.01 \\ 3.47 & 0.53 \pm 0.02 & 0.40 \pm 0.01 \\ 3.81 & 0.64 \pm 0.03 & 0.48 \pm 0.01 \\ 5.27 & 1.12 \pm 0.03 & 0.88 \pm 0.02 \\ 5.06 & 0.98 \pm 0.03 & 0.71 \pm 0.02 \\ 5.20 & 0.97 \pm 0.03 & 0.70 \pm 0.02 \\ 5.54 & 1.05 \pm 0.03 & 0.83 \pm 0.02 \\ 5.31 & 1.04 \pm 0.03 & 0.79 \pm 0.02 \\ 5.43 & 1.04 \pm 0.03 & 0.64 \pm 0.02 \\ 4.87 & 0.90 \pm 0.03 & 0.64 \pm 0.02 \\ 5.42 & 1.04 \pm 0.03 & 0.81 \pm 0.02 \\ 5.60 & 1.14 \pm 0.03 & 0.87 \pm 0.02\end{array}$

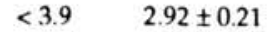

$<6.4$ $7.4 .28 \pm 0.22$ $7.6 \pm 1.7 \quad 4.0 \pm 0.22$ $3.8 \pm 1.5 \quad 2.52 \pm 0.19$ $<4.5 \quad 2.82 \pm 0.20$ $3.7 \pm 1.5 \quad 2.26 \pm 0.19$ $<5.8 \quad 2.45 \pm 0.19$ $<3.4 \quad 2.27 \pm 0.19$ $<5.2 \quad 2.14 \pm 0.19$ $4.9 \pm 1.7 \quad 3.25 \pm 0.21$ $<4.4 \quad 2.83 \pm 0.19$ $<3.6 \quad 1.89 \pm 0.17$ $<2.7 \quad 1.48 \pm 0.16$ $<2.8 \quad 1.16 \pm 0.15$ $<2.6 \quad 1.64 \pm 0.17$ $<5.4 \quad 1.69 \pm 0.17$ $<4.4 \quad 2.15 \pm 0.19$ $3.09 \pm 0.20$ $4.3 \pm 1.4 \quad 1.80 \pm 0.17$ $\begin{array}{ll}<.5 & 2.31 \pm 0.20\end{array}$
$0.642 \pm 0.018$ $0.671 \pm 0.019$ $0.649 \pm 0.019$ $0.612 \pm 0.017$ $0.629 \pm 0.018$ $0.632 \pm 0.017$ $0.640 \pm 0.018$ $0.623 \pm 0.017$ $0.651 \pm 0.018$ $0.627 \pm 0.017$ $0.534 \pm 0.015$ $0.480 \pm 0.014$ $0.468 \pm 0.013$ $0.547 \pm 0.015$ $0.562 \pm 0.016$ $0.632 \pm 0.017$ $0.650 \pm 0.018$ $0.556 \pm 0.016$ $0.698 \pm 0.019$ $0.841 \pm 0.026$ $0.734 \pm 0.025$ $0.831 \pm 0.028$ $0.651 \pm 0.022$ $0.724 \pm 0.025$ $0.657 \pm 0.023$ $0.602 \pm 0.022$ $0.506 \pm 0.019$ $0.565 \pm 0.021$ $0.647 \pm 0.022$ $0.853 \pm 0.028$ $0.846 \pm 0.028$ $0.850 \pm 0.028$ $0.892 \pm 0.029$ $0.788 \pm 0.027$ $0.892 \pm 0.029$ $0.721 \pm 0.026$ $0.748 \pm 0.027$ $0.733 \pm 0.026$

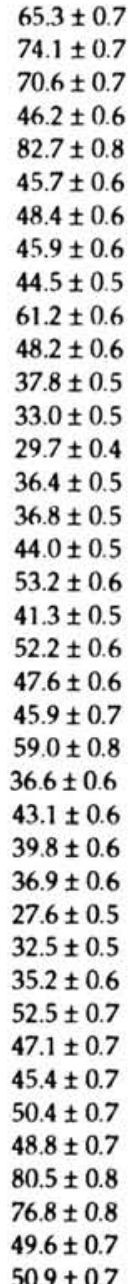

$65.3 \pm 0.7$

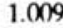

$35.17 \pm 0.93$
$36.44 \pm 0.98$

$0.55 \pm 0.04$ $\begin{array}{lll}1.067 & 36.44 \pm 0.98 & 0.76 \pm 0.04\end{array}$ $\begin{array}{lll}0.961 & 39.28 \pm 0.97 & 0.72 \pm 0.04\end{array}$ $\begin{array}{lll}0.947 & 34.69 \pm 0.87 & 0.45 \pm 0.03\end{array}$ $\begin{array}{lll}0.997 & 34.36 \pm 0.90 & 0.51 \pm 0.03\end{array}$ $\begin{array}{lll}0.923 & 33.89 \pm 0.87 & 0.36 \pm 0.03\end{array}$ $\begin{array}{lll}0.798 & 26.33 \pm 0.84 & 0.32 \pm 0.03\end{array}$ $\begin{array}{lll}0.866 & 29.35 \pm 0.84 & 0.44 \pm 0.03\end{array}$ $\begin{array}{lll}0.966 & 32.98 \pm 0.87 & 0.45 \pm 0.03\end{array}$

$\begin{array}{llll}0.982 & 30.65 \pm 0.86 & 0.46 \pm 0.03 & 1.728 \pm 0.061\end{array}$ $\begin{array}{llll}0.820 & 23.83 \pm 0.76 & 0.33 \pm 0.03 & 1.859 \pm 0.060\end{array}$ $\begin{array}{llll}0.728 & 20.87 \pm 0.71 & 0.25 \pm 0.03 & 1.642 \pm 0.056\end{array}$ $\begin{array}{llll}0.509 & 14.74 \pm 0.66 & 0.16 \pm 0.03 & 1.002 \pm 0.050\end{array}$ $\begin{array}{llll}0.837 & 23.60 \pm 0.77 & 0.28 \pm 0.03 & 1.510 \pm 0.058\end{array}$ $\begin{array}{llll}0.888 & 24.34 \pm 0.77 & 0.31 \pm 0.03 & 1.768 \pm 0.060\end{array}$ $\begin{array}{llll}0.972 & 26.75 \pm 0.84 & 0.35 \pm 0.03 & 1.715 \pm 0.062\end{array}$ $\begin{array}{llll}1.028 & 28.77 \pm 0.88 & 0.37 \pm 0.03 & 1.703 \pm 0.063\end{array}$ $\begin{array}{llll}0.830 & 26.13 \pm 0.77 & 0.29 \pm 0.03 & 1.630 \pm 0.058\end{array}$

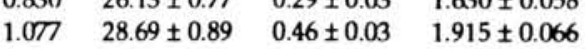

Symmetric errors for iridium measurement are the estimated one sigma values of the accuracy with Gaussian statistics. Upper and lower asymmetric errors each reflect $84 \%$ confidence levels with Poisson statistics.

For all other elements, the listed errors are estimated one sigma values of the ptecision of measurement. The precisions for unlisted errors are $-1 \%$. The precisions in this work should only be used for determining uncertainties in the ratios of the abundances of different elements in the same sample. Except for Ir, there is a $5 \%$ uncertainty in the abundances of all elements due to changes in reactor flux with sample position. $\mathrm{Zn}$ has an additional $-10 \%$ uncertainty because it is calibrated with a flux monitor

${ }^{a}$ Symmetric errors for iridium measurement are the estimated one sigma values of the accuracy with Gaussian statistics. Upper and lower asymmetric errors each reflect $84 \%$ confidence levels with Poisson statistics. For all other elements, the listed errors are estimated one sigma values of the precision of measurement. The precisions for unlisted errors are $\sim 1 \%$. The precisions in this work should only be used for determining uncertainties in the ratios of the abundances of different elements in the same sample. Except for Ir, there is a $5 \%$ uncertainty in the abundances of all elements due to changes in reactor flux with sample position. $\mathrm{Zn}$ has an additional $-10 \%$ uncertainty because it is calibrated with a flux monitor. 